\title{
Experimental Investigation of the Biomass Catalytic Pyrolysis Process to Produce the Combustible Gases with the High Calorific Value
}

\author{
Yury Kosivtsov, Esther Sulman*), Yury Lugovoy, Anna Kosivtsova, Antonina \\ Stepacheva
}

Department of Biotechnology and Chemistry, Tver State Technical University, A.Nikitina str., 22, Tver 170026, Russia

Received: 29th July 2015; Revised: 2nd December 2015; Accepted: 30th December 2015

\section{Abstract}

The study is devoted to the low-temperature catalytic pyrolysis of biomass. The pyrolysis of peat was conducted using natural aluminosilicates and synthetic zeolites. It was found that the pore size of the mineral strongly affects the catalytic activity and provides the processing of the hydrocarbons formation reactions. Bentonite clay was found to be the most effective catalyst for the biomass pyrolysis process. The use of bentonite clay as an addition to peat allows improving structural (strength, porosity) and sorption characteristics (sorption rate) of the molded compositions and can serve as a catalyst during its subsequent thermal conversion. The amount of gases obtained using natural aluminosilicate as a catalyst increased by 2 times compared to the non-catalytic process. The calorific value of the products obtained was higher due to the light hydrocarbons formation. (C) 2015 BCREC UNDIP. All rights reserved.

Keywords: Pyrolysis; biomass; aluminosilicate; zeolite

How to Cite: Kosivtsov, Y., Sulman, E., Lugovoy, Y., Kosivtsova, A., Stepacheva, A. (2015). Experimental Investigation of the Biomass Catalytic Pyrolysis Process to Produce the Combustible Gases with the High Calorific Value. Bulletin of Chemical Reaction Engineering \& Catalysis, 10 (3): 324-331. (doi:10.9767/bcrec.10.3.8869.324-331)

Permalink/DOI: http://dx.doi.org/10.9767/bcrec.10.3.8869.324-331

\section{Introduction}

The most prospective methods of thermochemical processing of biomass are pyrolysis and gasification, which consist of the heating of biomass at air tight or at the blowdown with water vapor, oxygen, carbon dioxide or their mixture to produce the combustible gases. The conversion of the initial feedstock is the com-

\footnotetext{
*) Corresponding Author.

E-mail: sulman@online.tver.ru (E. Sulman), Tel: +74-822-449348, Fax: +74-822-449317
}

plex system of the consecutive-competing opposite and complete reactions, among them there are exo- and endothermic reactions. Such processes have rather high activation energies, and hence they require high temperatures. The induction of the catalysts into the reaction system leads to the sufficient decrease in the activation energy and allows achieving higher amount of hydrocarbons in comparison to noncatalytic processes at the same temperature. Depending on the process conditions it is possible to obtain gas with the specified calorific value (3-30 $\left.\mathrm{MJ} / \mathrm{m}^{3}\right)$ and composition. The gases with calorific value to $7 \mathrm{MJ} / \mathrm{m}^{3}$ are used in the 
power industry and for the technological application. The calorific value of the suction gas obtained from wood and peat under the vapor-air purging is about $6 \mathrm{MJ} / \mathrm{m}^{3}$. The gases with the calorific value equal to $7 \mathrm{MJ} / \mathrm{m}^{3}$ are produced by the vapor-oxygen purging under pressure.

The studies focused on the investigation of the influence of type and composition of the mineral and organic compounds on the process rate and the yield of the pyrolysis products have the great importance for the biomass thermal processing field. The analysis of the interactions of the mixture components on the pyrolysis process contributes to the development of the scientific bases of the method, allows specifying the optimal substrate composition that leads to the increase in the effectiveness of the process. All these aspects help choosing the effective catalytic system which allows conducting the process at lower temperatures with high rates and selectivity [1-3].

The closed circuit of the pyrolysis process allows decreasing negative effects on the environment due to the decrease in the emission of adverse semi-products of the process. The use of the pyrolysis catalysts and the appliance of modern technologies of the process management allow increasing selectivity and conversion to the target products (gaseous and liquid fuels) that sufficiently increases the process effectiveness and decreases the feedstock processing cost $[4,5]$.

Leading European countries and the USA actively develop novel catalytic materials for the pyrolysis and gasification of organogeneous raw-materials. The examples are: zeolites ZSM5 [6], zeolites catalyst DC-11 [7], mineral silicaalumina materials MCM-41 [8], Al-MCM-41, Al-SBA-15 [9, 10], silica, $\mathrm{Al}_{2} \mathrm{O}_{3}, \gamma-\mathrm{Fe}_{2} \mathrm{O}_{3}, \mathrm{Fe}_{3} \mathrm{O}_{4}$, $a-\mathrm{FeOOH}$ [11], clays [12], $\mathrm{Ni} / \mathrm{Al}$ [13], boric and phosphoric acids [14], zinc chloride [15], $\mathrm{KNO}_{3}$ $\mathrm{B}_{2} \mathrm{O}_{3} / \mathrm{Al}_{2} \mathrm{O}_{3}$ [16], $\mathrm{Co} / \mathrm{MgO}$ [17]. Catalysts on the base of zeolites and like-zeolites minerals are the most prospective ones for the thermal treatment of biofuels. Thus the affectivity of thermochemical conversion of biomass to fuels is considerably increase while using silica-alumina catalysts which accelerate the decomposition of high-molecular substances, increase selectivity, allow controlling the obtaining of the products having the required volatility and inflammability limit.

The investigation of the influence of the catalytic properties of aluminosilicate materials (clays) on the biomass pyrolysis process was carried out. The aim of this study was the search of the effective catalyst for such biofuel processing. The choice of the clays and other aluminosilicate materials as the catalysts of the pyrolysis and gasification is based on the effectiveness of their influence on the organic compounds conversion. Moreover the availability and hence the low cost of the catalytic active mineral compounds also are of great interest.

\section{Materials and Method}

\subsection{Experimental set-up}

The experimental set-up for the pyrolysis methods approbation consists of the steel-batch reactor of the fixed type, electrical heater with the temperature regulation by contact thermocouple (see Figure 1). The flat heating of the electrical heater is $1000{ }^{\circ} \mathrm{C}$. The reactor is equipped with sample-collecting device, hydraulic seal and hose system for the transportation and collection of the gaseous products in the eudiometer.

The pyrolysis reactor type is chosen on the base of technical parameters such as heattransfer and feedstock supply type. In compliance with the literature data [18-24] while processing the biomass with the sufficient impurity, it is rational to use the reactors of the fixed type which excludes the stirring stages. The choice of the material must be based on the working process conditions: temperature, pressure and hostile medium.

\subsection{Pyrolysis Procedure}

Both natural aluminosilicate materials (caolin, bentonite, Cambrian clays and clay mergel) and synthetic zeolites (H-Beta-25, $\mathrm{H}$ Beta-150, HY, H-ZSM-5 and H-Mord-20, purchased from "Zeolyst International") were used as the catalysts of the biomass pyrolysis. To estimate the rates of thermodestruction of the feedstock in the presence of the catalysts the

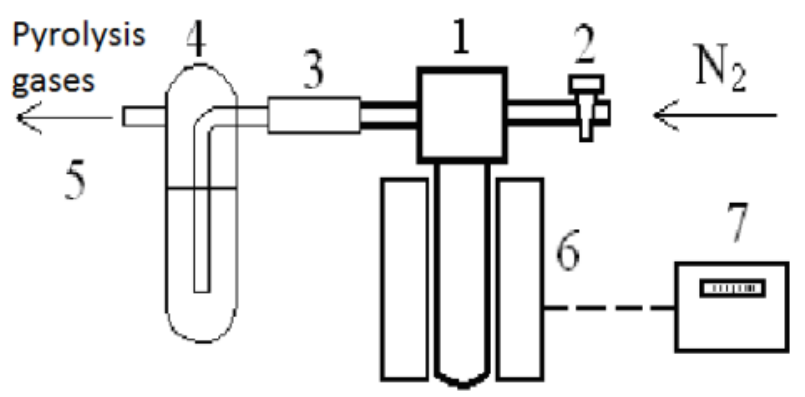

Figure 1. Scheme of the experimental set-up for the pyrolysis methods testing: (1) reactor, (2) faucet; (3) sample-collecting device; (4) hydraulic seal; (5) gas to the eudiometer; (6) electrical heater; (7) automatic regulator of temperature 
gaseous product evolution velocity was defined during the experiment. For the maximal effectiveness of the process the biomass pyrolysis temperature generally does not exceed $600{ }^{\circ} \mathrm{C}$ [22], that's why the working range of the temperatures of the experimental settlement is generally $300-600^{\circ} \mathrm{C}$. The duration of the process must not exceed 3-5 hours [25]. Therefore the range of the studied temperatures of the pyrolysis process was $400-600{ }^{\circ} \mathrm{C}$ and the duration of the experiment was $100 \mathrm{~min}$.

\subsection{Methods of the Analysis}

As the condensation processes of the nonvolatile liquid process products pass in the hydraulic seal, the liquid sample of the pyrolysis products can be collected at the end of the experiment for the analysis by the methods of IRspectrometry, liquid chromatography and chromate-mass-spectrometry.

The gaseous product volume measurement was carried out by the eudiometer. The collection of the gaseous products was preceded from both the sample-collector and the eudiometer for the following analysis by the gas chromatography and gaseous chromate-massspectrometry methods. The masses of the solid residue and the liquid fraction were calculated by the difference of the masses of the reactor and the hydraulic seal, respectively.

The analysis of the elemental composition of the aluminosilicate minerals was carried out using X-ray fluorescent spectrometer "Spectroscan-Max". The surface area and pore distribution of the studied clays were defined by the analyzer Beckman CoulterTM SA 3100TM.

To estimate the concentration of hydrocarbons of a gaseous mixture obtained by the pyrolysis the gaseous chromatograph "Model 3700" equipped with the column filled with silica gel was used [26]. The analysis conditions were the followings: the consumption of gas-carrier (nitrogen) $120 \mathrm{~mL} / \mathrm{min}$; gas-carrier pressure $1.5 \mathrm{~kg} \mathrm{~s} / \mathrm{sm}^{3}$; duration of the analysis $30 \mathrm{~min}$; sample volume $1 \mathrm{~mL}$; carrier-silica gel $0.4 \mathrm{~mm}$; column length $1 \mathrm{~m}$; column temperature $50{ }^{\circ} \mathrm{C}$; detector temperature $100{ }^{\circ} \mathrm{C}$.

To estimate the calorific value of the obtained gaseous products the analyzer of the volumetric specified calorific value of the gases was developed on the base of flame temperature detector [26].

\section{Results and Discussion}

\subsection{Catalysts Characterisation}

The surface characteristics of the catalytic systems H-Beta-25 and H-MORD are presented in Table 1. During the experiments on biomass pyrolysis the elemental composition of natural zeolites, their surface areas and pore-size distribution were investigated. The results of the analysis are presented in Table 2.

The data obtained show that bentonite clay consists of the significant amount of Fe that indicates the presence of the ferrous montmorillonite in it. At the same time Fe concentration of

Table 2. The elemental composition of the clays studied

\begin{tabular}{cc}
\hline Component & Concentration, \% \\
\hline \multicolumn{2}{c}{ Bentonite clay } \\
\hline $\mathrm{Al}_{2} \mathrm{Si}_{4} \mathrm{O}_{13} \mathrm{H}_{4}$ & 96.88 \\
$\mathrm{Ti}$ & 0.46 \\
$\mathrm{Mn}$ & 0.06 \\
$\mathrm{Fe}$ & 2.47 \\
$\mathrm{Ag}$ & 0.05 \\
\hline \multicolumn{2}{c}{ Caolin clay } \\
\hline $\mathrm{Al}_{2} \mathrm{Si}_{2} \mathrm{O}_{6} \mathrm{H}_{4}$ & 99.48 \\
$\mathrm{Fe} \quad 0.34$ \\
\hline \multicolumn{2}{c}{ Clay mergel } \\
\hline $\mathrm{Al}_{2} \mathrm{Si}_{4} \mathrm{O}_{6} \mathrm{H}_{2}$ & 97.56 \\
$\mathrm{Mn}$ & 0.07 \\
$\mathrm{Fe}$ & 2.20 \\
\hline
\end{tabular}

Table 1. The surface area and pore size of H-Beta-25 and H-MORD

\begin{tabular}{|c|c|c|c|c|c|}
\hline $\begin{array}{c}\text { Synthetic } \\
\text { zeolites }\end{array}$ & \multicolumn{4}{|c|}{ Pore size, $\AA$} & $\begin{array}{c}\text { Surface } \\
\text { area, } \mathrm{m}^{2 / g}\end{array}$ \\
\hline \multirow[b]{2}{*}{ H-Beta-25 } & \multicolumn{2}{|c|}{ Polymorph A } & \multicolumn{2}{|c|}{ Polymorph B } & \\
\hline & $\begin{array}{c}\text { Straight channel } \\
\quad 7.3 \times 6.0\end{array}$ & $\begin{array}{c}\text { Tortuous } \\
\text { channel } \\
5.6 \times 5.6\end{array}$ & $\begin{array}{l}\text { Straight } \\
\text { channel } \\
7.3 \times 6.8\end{array}$ & $\begin{array}{c}\text { Tortuous } \\
\text { channel } \\
5.5 \times 5.5\end{array}$ & 807 \\
\hline H-MORD & $\begin{array}{r}\text { Transversal s } \\
\text { chan } \\
6.7 \mathrm{x}\end{array}$ & ms of the & $\begin{array}{r}\text { Transversa } \\
\text { ch } \\
2 .\end{array}$ & ns of the & 605 \\
\hline
\end{tabular}


the caolin clay is twice as much as it is of the bentonite clay. But the presence of the catalytic active elements is insufficient for the catalysts activity, these elements must be available for the compounds which are exposed to the catalytic transformation. The objective factor of the availability of the catalytic sites is the value of the specific surface area of the catalysts. The specific surface area and the pore volume reach the maximum value for the bentonite clay (Table 3 and 4). The presence of the pores with different sizes in the studied clays samples positively affects hydrocarbons synthesis. The pore large size promotes fast delivery of the reactants to the catalytic sites and fast rejection of the reaction products, the pores with small size provide hydrocarbons synthesis [27]. The results of the pore-size distribution investigation (Table 4) indicate that generally the structure of all studied samples of the catalysts is presented by the mesopores.

\subsection{Catalysts Testing}

The catalytic activity of natural aluminosili-

Table 3. The specific surface of the clays samples

\begin{tabular}{cccccc}
\hline \multirow{2}{*}{ The clay type } & \multicolumn{4}{c}{ Specific surface area S, m²/g } \\
\cline { 2 - 3 } \cline { 5 - 6 } \cline { 5 - 6 } \cline { 5 - 6 } & \multicolumn{2}{c}{ Langmuir model } & $\mathrm{K}$ & & \multicolumn{2}{c}{ BET model } \\
\cline { 2 - 3 } & $\mathrm{S}_{\mathrm{L}}$ & 0.99980 & & 9.103 & $\mathrm{~K}$ \\
\hline Caolin clay & 9.554 & & 58.910 & 0.99997 \\
Bentonite clay & 59.821 & 0.99970 & & 20.420 & 0.99997 \\
Clay mergel & 18.923 & 0.99980 & &
\end{tabular}

cates and synthetic zeolites was estimated by the volume of the gaseous mixture obtained in the biomass pyrolysis process and by the values of hydrocarbons concentration and calorific value of the combustible gases.

It is shown that in the presence of natural aluminosilicate materials biomass pyrolysis leads to the increase in the volume of the resulting pyrolysis gas. From the data shown in the Table 5, it can be seen that the volume of the gas mixture obtained in the biomass pyrolysis in the presence of, e.g.: bentonite clay, is increased by about 1.2 times compared to a noncatalytic process that indicates that the reaction is catalyzed by the active sites of aluminosilicate. Moreover the catalytic action of studied aluminosilicates is associated generally with the presence of acid sites due to the negligible amount of transition metals in clays (Table 2). Furthermore according to the data presented in Table 3 bentonite clay has the highest surface area among the other clays that also influences on the performance of the catalyst.

Table 4. Pore size distribution

\begin{tabular}{|c|c|c|c|c|c|c|}
\hline \multirow{2}{*}{$\begin{array}{l}\text { Pore di- } \\
\text { ameter, } \\
\text { nm }\end{array}$} & \multicolumn{2}{|c|}{ Bentonite clay } & \multicolumn{2}{|c|}{ Caolin clay } & \multicolumn{2}{|c|}{ Clay mergel } \\
\hline & $\begin{array}{c}\text { Pore volume, } \\
\mathrm{mL} / \mathrm{g}\end{array}$ & $\%$ & $\begin{array}{c}\text { Pore volume, } \\
\mathrm{mL} / \mathrm{g}\end{array}$ & $\%$ & $\begin{array}{c}\text { Pore volume, } \\
\mathrm{mL} / \mathrm{g}\end{array}$ & $\%$ \\
\hline$<6$ & 0 & 0 & 0.00271 & 16.40 & 0 & 0 \\
\hline $8-6$ & 0 & 0 & 0.00166 & 10.06 & 0 & 0 \\
\hline $8-10$ & 0 & 0 & 0.00133 & 8.06 & 0 & 0 \\
\hline $10-12$ & 0.00201 & 0.11 & 0.00134 & 8.10 & 0.00116 & 0.12 \\
\hline $12-16$ & 0.00968 & 0.51 & 0.00161 & 9.77 & 0.00504 & 0.53 \\
\hline $16-20$ & 0.01396 & 0.73 & 0.00144 & 8.73 & 0.01027 & 1.08 \\
\hline $20-80$ & 1.89008 & 98.65 & 0.00512 & 31.00 & 0.69005 & 72.48 \\
\hline$>80$ & 0.00020 & 0.01 & 0.00130 & 7.89 & 0.24558 & 25.79 \\
\hline Total & 1.91593 & 100 & 0.01651 & 100 & 0.95210 & 100 \\
\hline
\end{tabular}


The study of the catalytic activity of synthetic zeolite in the biomass pyrolysis processes has shown that the amount of the pyrolysis gas increases approximately by 1.3-1.7 times compared to the processes carried out both without catalysts and with the addition of aluminosilicate minerals (Table 5). The higher catalytic activity of zeolites compared with natural aluminosilicates can be explained by the higher specific surface area (Tables 1 and 3) that is one of the determinant factor.

When using clay minerals, a significant increase in the amount of hydrocarbons released in the gas mixture was observed. Their values were more than 2 times higher than the values obtained in the pyrolysis of the sample containing no catalyst (Table 6). It is noteworthy that the largest amount of ethylene and propane was obtained when using bentonite clay, which is important in the evaluation of the calorific value of the combustible mixture because these hydrocarbons have a higher heat value compared to ethane and methane. It is noteworthy that bentonite clay is characterized by the highest volume of mesopores with diameter 20$80 \mathrm{~nm}$ (Table 4) which as it was indicated in 3.1

Table 5. Dependence of the amount of released gases on the nature of the catalyst

\begin{tabular}{ccccccc}
\hline \multirow{2}{*}{ Time, s } & \multicolumn{6}{c}{ Volume, ml } \\
\cline { 2 - 7 } & $\begin{array}{c}\text { Without } \\
\text { catalyst }\end{array}$ & Bentonite clay & Clay mergel & Caolin clay & H-Beta-25 & H-MORD \\
\hline 0 & 0 & 0 & 0 & 0 & 0 & 0 \\
360 & 29.0 & 29.0 & 40.0 & 26.0 & 59.7 & 80.4 \\
840 & 89.0 & 95.0 & 120.0 & 85.0 & 160.0 & 175.5 \\
1320 & 117.5 & 136.5 & 151.0 & 122.0 & 192.1 & 202.7 \\
1800 & 130.0 & 152.5 & 166.0 & 137.0 & 210.3 & 226.0 \\
3360 & 152.0 & 181.5 & 194.0 & 165.5 & 232.6 & 260.4 \\
\hline
\end{tabular}

Table 6. Dependence of the accumulation of hydrocarbons on the nature of the catalyst

\begin{tabular}{|c|c|c|c|c|c|c|c|}
\hline \multirow{2}{*}{$\begin{array}{l}\text { Hydro- } \\
\text { carbons }\end{array}$} & \multirow{2}{*}{ Time, s } & \multicolumn{6}{|c|}{ The accumulation of hydrocarbons, mol } \\
\hline & & $\begin{array}{l}\text { Without } \\
\text { catalyst }\end{array}$ & $\begin{array}{c}\text { Bentonite } \\
\text { clay }\end{array}$ & Caolin clay & Clay mergel & H-Beta-25 & H-MORD \\
\hline \multirow{6}{*}{ Methane } & 0 & 0 & 0 & 0 & 0 & 0 & 0 \\
\hline & 360 & $0.04 \cdot 10^{-5}$ & $0.05 \cdot 10^{-5}$ & $0.07 \cdot 10^{-5}$ & $0.07 \cdot 10^{-5}$ & $0.62 \cdot 10^{-5}$ & $0.81 \cdot 10^{-5}$ \\
\hline & 840 & $1.45 \cdot 10^{-5}$ & $3.26 \cdot 10^{-5}$ & $3.87 \cdot 10^{-5}$ & $3.16 \cdot 10^{-5}$ & $12.71 \cdot 10^{-5} 0$ & $21.98 \cdot 10^{-5}$ \\
\hline & 1320 & $4.64 \cdot 10^{-5}$ & $9.09 \cdot 10^{-5}$ & $8.98 \cdot 10^{-5}$ & $8.90 \cdot 10^{-5}$ & $26.50 \cdot 10^{-5}$ & $34.17 \cdot 10^{-5}$ \\
\hline & 1800 & $7.57 \cdot 10^{-5}$ & $14.50 \cdot 10^{-5}$ & $13.40 \cdot 10^{-5}$ & $14.50 \cdot 10^{-5}$ & $38.36 \cdot 10^{-5}$ & $42.98 \cdot 10^{-5}$ \\
\hline & 3360 & $16.40 \cdot 10^{-5}$ & $29.60 \cdot 10^{-5}$ & $29.60 \cdot 10^{-5}$ & $30.00 \cdot 10^{-5}$ & $49.53 \cdot 10^{-5}$ & $55.64 \cdot 10^{-5}$ \\
\hline \multirow{7}{*}{ Ethane } & 0 & 0 & 0 & 0 & 0 & 0 & 0 \\
\hline & 360 & $0.019 \cdot 10^{-5}$ & $0.02 \cdot 10^{-5}$ & $0.02 \cdot 10^{-5}$ & $0.01 \cdot 10^{-5}$ & $0.11 \cdot 10^{-5}$ & $0.13 \cdot 10^{-5}$ \\
\hline & 840 & $0.54 \cdot 10^{-5}$ & $0.97 \cdot 10^{-5}$ & $0.72 \cdot 10^{-5}$ & $0.68 \cdot 10^{-5}$ & $3.41 \cdot 10^{-5}$ & $8.21 \cdot 10^{-5}$ \\
\hline & 1320 & $1.41 \cdot 10^{-5}$ & $2.55 \cdot 10^{-5}$ & $1.73 \cdot 10^{-5}$ & $1.96 \cdot 10^{-5}$ & $8.05 \cdot 10^{-5}$ & $9.25 \cdot 10^{-5}$ \\
\hline & 1800 & $2.08 \cdot 10^{-5}$ & $4.28 \cdot 10^{-5}$ & $2.72 \cdot 10^{-5}$ & $3.32 \cdot 10^{-5}$ & $8.25 \cdot 10^{-5}$ & $9.32 \cdot 10^{-5}$ \\
\hline & 3360 & $4.45 \cdot 10^{-5}$ & $10.50 \cdot 10^{-5}$ & $7.09 \cdot 10^{-5}$ & $8.61 \cdot 10^{-5}$ & $8.35 \cdot 10^{-5}$ & $9.41 \cdot 10^{-5}$ \\
\hline & 3360 & $1.71 \cdot 10^{-5}$ & $6.28 \cdot 10^{-5}$ & $3.31 \cdot 10^{-5}$ & $3.91 \cdot 10^{-5}$ & $3.90 \cdot 10^{-5}$ & $3.13 \cdot 10^{-5}$ \\
\hline \multirow{6}{*}{ Propane } & 0 & 0 & 0 & 0 & 0 & 0 & 0 \\
\hline & 360 & 0 & $0.07 \cdot 10^{-5}$ & 0 & 0 & $1.31 \cdot 10^{-5}$ & $0.15 \cdot 10^{-5}$ \\
\hline & 840 & $0.25 \cdot 10^{-5}$ & $1.29 \cdot 10^{-5}$ & $0.37 \cdot 10^{-5}$ & $0.03 \cdot 10^{-5}$ & $4.35 \cdot 10^{-5}$ & $3.42 \cdot 10^{-5}$ \\
\hline & 1320 & $0.66 \cdot 10^{-5}$ & $2.56 \cdot 10^{-5}$ & $0.87 \cdot 10^{-5}$ & $0.95 \cdot 10^{-5}$ & $5.26 \cdot 10^{-5}$ & $3.65 \cdot 10^{-5}$ \\
\hline & 1800 & $0.99 \cdot 10^{-5}$ & $3.55 \cdot 10^{-5}$ & $1.34 \cdot 10^{-5}$ & $1.58 \cdot 10^{-5}$ & $5.36 \cdot 10^{-5}$ & $3.84 \cdot 10^{-5}$ \\
\hline & 3360 & $2.02 \cdot 10^{-5}$ & $6.51 \cdot 10^{-5}$ & $3.23 \cdot 10^{-5}$ & $3.86 \cdot 10^{-5}$ & $5.42 \cdot 10^{-5}$ & $4.29 \cdot 10^{-5}$ \\
\hline
\end{tabular}


affect on the hydrocarbons formation [27].

The use of synthetic zeolites into the biomass pyrolysis leads to the sharp increase in the concentration of lower hydrocarbons such as methane in the resulting gaseous mixture as it is shown in Table 6. The values obtained show that the amount of the components is increased more than by four times compared to the results of a non-catalytic process and is approximately 2 times higher than the same data of the catalytic activity of bentonite clay in the pyrolysis of biomass. The amount of other separated hydrocarbons (ethane, ethylene, and propane) increases not more than twice compared to the non-catalytic process, and the data obtained using bentonite clay is higher than those obtained using synthetic zeolites. It indicates the prevalence of decomposition processes over the processes of synthesis (including FischerTröpsch synthesis) that can be caused by a small (relative to clay) pore size, therefore, there is no orientation of the molecules for the synthesis of hydrocarbons having a chain length of 2-3 carbon atoms (Tables 1 and 4).

The increase in the number of hydrocarbons explains the increase in the calorific value of the pyrolysis gases; the value was 2 times higher compared to the data obtained for the process without the addition of the catalysts (Table 7). Among of number of aluminosilicate minerals that were used in this work, bentonite clay was the most effective. When this catalyst was used, the resulting amount of ethylene and propane, and the calorific value of the pyrolysis gases were the highest (Tables 6 and 7). Further experiments were carried out in the presence of bentonite clay which was considered the most effective catalyst.

When using synthetic zeolites the increase in the calorific value of the combustible gases obtained was observed. This value exceeds similar results of the non-catalytic process by more than 2 times (Table 7). The calorific value has similar level when the two samples of synthetic zeolites were used as catalysts in comparison with natural aluminosilicate minerals. This can be explained by the fact that in the presence of synthetic zeolites the volume of the released pyrolysis gas was about 1.4 times higher (a significant portion makes methane (Table 6)). The latter has a lower calorific value than ethylene and propane, accumulated when using bentonite clay.

The study of the dependence of calorific value of the combustible gases on the concentration of bentonite clay (Table 8) allows concluding that the optimal concentration of bentonite clay for the pyrolysis of biomass is $2 \%$ (wt.) of the substrate mass. Natural aluminosilicates when present in significant amounts in the reaction mixture, besides having a catalytic function also acted as heat-carriers, considerably increasing the heat conductivity of the mixture, thus promoting more uniform heating. Depending on aluminosilicates concentration the factor of heat conductivity of reaction mixture can be varied from 0.08 up to $0.182 \mathrm{~W} /(\mathrm{m} . \mathrm{K})$.

Table 7. Dependence of the calorific value on the time

\begin{tabular}{ccccccc}
\hline \multirow{2}{*}{ Time, $\mathrm{s}$} & \multicolumn{6}{c}{$\mathrm{Q}, \mathrm{mJ} / \mathrm{m}^{3}$} \\
\cline { 2 - 7 } & $\begin{array}{c}\text { Without } \\
\text { catalyst }\end{array}$ & Bentonite clay & Caolin clay & Clay mergel & H-Beta-25 & H-MORD \\
\hline 0 & 0 & 0 & 0 & 0 & 0 & 0 \\
480 & 2.86 & 2.19 & 2.94 & 2.36 & 7.38 & 10.48 \\
960 & 3.53 & 5.50 & 4.73 & 4.15 & 9.71 & 11.21 \\
1440 & 4.37 & 7.84 & 5.50 & 5.65 & 13.13 & 13.95 \\
1920 & 5.72 & 10.57 & 7.02 & 7.00 & 14.35 & 14.03 \\
3600 & 7.82 & 15.21 & 10.66 & 10.70 & 16.25 & 14.30 \\
\hline
\end{tabular}

Table 8. Dependence of the calorific value of the gas mixture on the concentration of bentonite clay

\begin{tabular}{ccccccc}
\hline The concentration of bentonite clay, $\%$ & 1 & 2 & 3 & 4 & 5 & 10 \\
\hline $\mathrm{Q}, \mathrm{mJ} / \mathrm{m}^{3}$ & 7.31 & 11.11 & 10.53 & 10.84 & 8.94 & 8.22 \\
\hline
\end{tabular}




\section{Conclusions}

The study showed that the catalytic pyrolysis of biomass allows obtaining the combustible gas with a high calorific value. This fact opens the possibility of using catalytic pyrolysis in the field of alternative energy production.

As a result of the work the conditions of the catalytic conversion of biomass to produce a mixture of combustible gases using natural aluminosilicate minerals were defined. It was found that bentonite clay had the best catalytic effect on the peat pyrolysis process when it was introduced into the substrate at a concentration $2 \%$ (wt.) at a temperature $460-480{ }^{\circ} \mathrm{C}$. The use of the catalyst allows reducing biomass pyrolysis temperature to $450-480{ }^{\circ} \mathrm{C}$, which can significantly simplify the design of the pyrolyzer and allows using the cheaper materials for its construction.

\section{Acknowledgments}

The study was financially supported by the Ministry of Science and Education of the Russian Federation (RFMEFI57414X0075).

\section{References}

[1] Cunliffe, A.M., Jones, N., Williams, P.T. (2003) Pyrolysis of composite plastic waste. Environmental Technology, 24: 653-663.

[2] Dominguez, A. (2003) Conventional and microwave induced pyrolysis of coffee hulls for the production of a hydrogen rich fuel gas. Journal of Chromatography, 1012: 193-206.

[3] Matsumoto, Y. (2001) Aromatization of waste polyolefin pyrolysate over H-ZSM-5 zeolitesupported gallium oxide catalysts. J. Mat. Cycles Waste Man., 3: 82-87.

[4] Walendziewski, J. (2001). Thermal and catalytic conversion of waste polyolefins. Catal. Today, 65: 323-330.

[5] Satsuma, A., Ebigase, T., Inaki, Y., Yoshida, H., Kobayashi, S., Uddin, M.A., Sakata, Y., Hattori, T. (2001) Catalytic sites of mesoporous silica in degradation of polyethylene. Stud. Surf. Sci. Catal., 135: 277-285.

[6] Marcilla, A., Gomes, A., Menargues, S., García-Martínez, J., Cazorla-Amorós, D. (2003) Catalytic cracking of ethylene-vinyl acetate copolymers: comparison of different zeolites, Journal of Anal. Appl. Pyrolysis, 68-69: 495506.

[7] Serrano, D., Aguado, J., Escola, J., Rodríguez, J., Morselli, L., Orsi, R. (2003) Thermal behaviour during the pyrolysis of low rank perhydrous coals, Journal of Anal. Appl. Pyrolysis, 68-69: 481-494.
[8] Nierop, G., van Bergen, F. (2002) Clay and ammonium catalyzed reactions of alkanols, alkanoic acids and esters under flash pyrolytic conditions, Journal of Anal. Appl. Pyrolysis, 63: 197-208.

[9] Brebu, M., Azhar, M., Muto, A., Sakata, Y., Vasile, C. (2002) The role of temperature program and catalytic system on the quality of acrylonitrile-butadiene-styrene degradation oil, Journal of Anal. Appl. Pyrolysis, 63: 4357.

[10] Van Grieken, R., Serrano, D., Aguado, J., García, R., Rojo, C. (2001) Thermal and catalytic cracking of polyethylene under mild conditions, Journal of Anal. Appl. Pyrolysis, 5859: 127-142.

[11] García, L., Salvador, M.L., Arauzo, J., Bilbao, R. (2001) Catalytic pyrolysis of biomass: influence of the catalyst pretreatment on gas yields, Journal of Anal. Appl. Pyrolysis, 58-59: 491-501.

[12] Eun-Young, H., Jong-Ryeul, K., Jeong-Kun, C., Hee-Chul, W., Dae-Won, P. (2002) Performance of acid treated natural zeolites in catalytic degradation of polypropylene, Journal of Anal. Appl. Pyrolysis, 62: 351-364.

[13] Williams, P.T., Reed, A.R. (2004) High grade activated carbon matting derived from the chemical activation and pyrolysis of natural fibre textile waste, Journal of Anal. Appl. Pyrolysis, 71: 971-986.

[14] Jong, H.C., Sang, M.J., Jun, H.K., Sang, K.P., Won-Ho, L. (2004) Materials of $13^{\text {th }}$ International Congress on Catalysis, 2: 217.

[15] Kraikul, N., Jitkarnka, S., Luengnaruemitchai, A. (2005) Selective Catalytic Oxidation of $\mathrm{CO}$ in the Presence of $\mathrm{H}_{2}$ over Pt Supported on A Zeolite Catalysts, 7th World Congress of Chemical Engineering, 245.

[16] Tasaka, K., Furusawa, T., Tsutsumi, A. (2005) Biomass gasification in fluidised bed reactor with Co catalyst, $7^{\text {th }}$ World Congress of Chemical Engineering, 208.

[17] Simonov, A.D., Yazykov, N.A., Vedyakin, P.I., Parmon, V.N. (2003) Industrial experience of heat supply by catalytic installations, $3-d$ Russia-China Seminar on Catalysis, 35.

[18] Isoda, T., Nakahara, T., Kusakabe, K., Morooka, S. (1998) Catalytic cracking of polyethylene liquified oil over amorphous aluminosilicate catalysts. Energy Fuels, 12: 11611167.

[19] Gomez, M.A., Reyes Labarta, J.A. (2001) MCM-41 catalytic pyrolysis of ethylene-vinyl acetate copolymers: kinetic model. Polymer, 42: 8103-8111.

[20] Manos, G., Yusof, I.Y., Papayannakos, N., Gangas, N.H. (2001) Catalytic cracking of 
polyethylene over clay catalysts. Comparison with an ultrastable Y zeolite. Ind. Eng. Chem. Res., 40: 2220-2225.

[21] Gobin, K., Manos, G. (2004) Polymer degradation to fuels over microporous catalysts as a novel tertiary plastic recycling method. Polym. Deg. Stab., 83: 267-279.

[22] Serrano, D.P., Aguado, J., Escola, J.M., Rodr1guez, J.M. (2002) Nanocrystalline ZSM-5: a highly active catalyst for polyolefin feedstock recycling. Surf. Sci. Catal., 142: 77-84.

[23] Lin, R., White, R.L. (1995) Effects of catalyst acidity and HZSM-5 channel volume on the catalytic cracking of polyethylene. J. Appl. Polym. Sci., 58: 1151-1159.

[24] Chen, J.H., Chen, K.S., Tong, L.Y. (2001) On the pyrolysis kinetics of scrap automotive tires. Journal of Hazardous Materials, 84: 4355.
[25] Diez, C. (2004) Pyrolysis of tyres. Influence of the final temperature of the process on emissions and the calorific value of the products recovered. Waste Management, 24: 463-469.

[26] Ilyasov, L.V., Kislitsa, O.V., Alfyorov, V.V., Sulman, E.M., Sulman, M.G., Molchanov, V.P. (2004) Analyzer of the volume specific calorific value of gases. (Analizator ob'emnoy udelnoy teploty sgoraniya gasovyh sred). Patent of RF. \#38507.

[27] Zhang, Y., Yoneyama, P., Tsubaki, N. (2005) A New Low-Temperature Methanol Synthesis Method. 7th World Congress of Chemical Engineering, 10-14 July, Glasgow, Scotland: 256. 